3 Forest therapy involves engaging in a combination of forest-based activities to improve

4 one's health or wellbeing. We conducted an overview of systematic reviews (SRs) and

\section{Forest therapy can prevent and treat depression: evidence from meta-analyses} meta-analyses of primary studies to provide the most comprehensive summary of the effect of forest therapy on depression. We included 13 primary studies that matched our eligibility criteria - all were included in four recent SRs and were conducted in the Republic of Korea. We carried out meta-analyses with data extracted directly from these 13 studies and assessed their risk of bias. Outcomes of interest were depressive symptoms, temporary recovery from depression (i.e. remission), response to treatment (i.e. $\geq 50 \%$ reduction on depressive symptoms from baseline), adherence to treatment, and adverse effects. Considering pooled estimates from randomized controlled trials with adults, we found that compared to no intervention/usual care, forest therapy produced a greater reduction of depressive symptoms (Hedges' $g=1.18,95 \%$ CI $[0.86$, 1.50], $p<.00001)$. Also compared to no intervention/usual care, participants in the forest therapy group were 17 times as likely to achieve remission (Risk Ratio $=17.02$, $95 \% C I[3.40,85.21], p=.0006)$ and three times as likely to have a $\geq 50 \%$ reduction on depressive symptoms (Risk Ratio $=3.18,95 \% C I[1.94,5.21], p<.00001)$. Forest therapy, on average, reduced depressive symptoms more than engaging in similar activities in a hospital or non-forested urban area, or participating in an intervention focused on diet plus forest-based exercise. We did not find evidence that adherence to forest therapy is different from the adherence to alternative interventions and the adverse effects of forest therapy appear to be rare. These results indicate that, relative to many more conventional alternatives, forest therapy is a more effective short-term intervention for the prevention and treatment of depression in adults. 
1 Keywords: contact with nature; dysthymia; forest bathing; mental health; mood

2 disorder; shinrin-yoku

3

\section{1. Introduction}

5 Depression is considered one of the most important global health challenges (Cipriani et 6 al., 2018). More than 300 million people worldwide suffer from this disorder, which can 7 harm many aspects of life (e.g. affective relationships and work) and, in the worst-case 8 scenario, lead to suicide (World Health Organization, 2017). Common symptoms of

9 depression are sad mood, anxiety, insomnia, loss of vitality, and lack of interest in life

10 (Fried, 2017). Depression is best conceptualized in a continuum ranging from the

11 presence of a few/mild/rare symptoms to the presence of several/severe/frequent

12 symptoms that lead to a debilitating life condition (Fried, 2017; van de Leemput et al.,

13 2014). The diagnosis of a person as depressed is based on specific criteria and should

14 ideally be done through a structured or semi-structured interview (Nordgaard et al.,

15 2013). Considering that depression is understood as a combination of symptoms (Fried,

16 2017; van de Leemput et al., 2014), interventions designed to prevent or treat

17 depression should not focus solely on one symptom. By preventing depression, we refer

18 to a process in which a non-depressed person achieves a reduction in depressive

19 symptoms. Such a reduction helps this person to remain non-depressed. By treating

20 depression, we refer to a process in which a depressed person achieves a reduction in

21 depressive symptoms.

22 Common treatments for depression are psychotherapy and antidepressants

23 (Cuijpers, 2018). These have advantages, such as accessibility to treatment, and have

24 been proven to be efficient in ameliorating depressive symptoms (Cuijpers et al., 2020),

25 but they also present some disadvantages. For example, the use of antidepressants can 
1 have secondary effects like gastrointestinal symptoms (e.g. nausea and diarrhea), weight

2 gain, and metabolic abnormalities (Carvalho et al., 2016), and both antidepressants and

3 psychotherapy lack effectiveness in the short-term (Cuijpers, 2018). Considering these

4 disadvantages of psychotherapy and antidepressants, researchers have called for

5 complementary or even alternative treatments for depression (Lopresti, 2019;

6 Munkholm et al., 2019). One of these alternatives may be direct contact with nature

7 (Lee et al., 2017; Rajoo et al., 2020; van Tulleken et al., 2018). Specifically, previous

8 studies have found encouraging results regarding the potential of forest therapy to

9 prevent and treat depression (e.g. Chun et al., 2017; Kim et al., 2009).

10 The human health benefits of exposure to trees and forests abound and include

11 restorative capacities such as stress reduction as well as improvement in clinical mental

12 health outcomes (Wolf et al., 2020). To maximize these capacities, forest therapy is

13 often recommended as a form of preventive medicine (Park et al., 2010). Forest therapy,

14 also known as "shinrin-yoku”(Oh et al., 2017; Park et al., 2010; Rajoo et al., 2020),

15 involves engaging in a combination of activities in a forest environment to improve

16 one's health or wellbeing (Han et al., 2016; Lee et al., 2017; Yu and Hsieh, 2020).

17 Forest therapy may include forms of forest-based exercise but should involve more than

18 just physical activity - typically incorporating other activities that foster positive mental

19 health such as meditation, games using forest elements, and/or group activities (Bang et

20 al., 2018; Chun et al., 2017; Djernis et al., 2019; Han et al., 2016; Lee et al., 2017;

21 Rajoo et al., 2019). In urban environments that increase stress and hinder psychological

22 restoration, direct immersion in forests can help people to calm down and reflect

23 (Collado et al., 2017; Kaplan, 1995; Kim et al., 2009; Kotera et al., 2020; Mayer et al.,

24 2009; Rajoo et al., 2019). There is evidence that even a short period spent in a forest can

25 help people reduce stress, recover their attentional capabilities, and shift towards more 
1 positive emotions (Djernis et al., 2019; Kaplan, 1995; Kotera et al., 2020; Lee et al.,

2 2017; Rajoo et al., 2020; Wen et al., 2019; Yu and Hsieh, 2020). These benefits of

3 exposure to forests provide insights regarding the value of forest environments and the

4 relevance of conserving and utilizing these settings to improve human health (Bratman

5 et al., 2019).

6 Yet, while an abundance of research suggests forest-based activities produce

7 positive health outcomes (Hansen et al., 2017; Park et al., 2010), less research has

8 explored direct links between forest therapy and depression (Wen et al., 2019). For

9 example, in Wen et al.'s (2019) study of the effects of forest activities on health, only

10 three out of the 28 studies included in their analyses reported the effect of forest therapy

11 on depression. Furthermore, because previous evidence synthesis combined results from

12 depression measures with other constructs, it is difficult to discern if forest therapy is an

13 effective way of preventing and treating depression, specifically (Djernis et al., 2019;

14 Kotera et al., 2020). It is also unknown if forest therapy is safe (i.e. are adverse effects

15 rare?) and acceptable (i.e. do people adhere well to forest therapy?). Such knowledge

16 gaps limit the development of guidelines for practitioners who might be willing to

17 employ forest therapy to prevent and treat depression.

18 We therefore conducted an overview of systematic reviews (SRs) and meta-

19 analyses to answer the following research question: Is there sufficient evidence

20 supporting forest therapy as an effective intervention to prevent and treat depression?

21 Our literature review offers four novel contributions. First, to our knowledge, this is the

22 first review to focus exclusively on the effects of forest therapy on depression. Second,

23 we included more primary studies that reported depression outcomes than previous SRs,

24 and used these studies to provide estimates of the effect of forest therapy on depression.

25 Third, in addition to previous reviews that primarily focused on the alleviation of 
1 depressive symptoms based on statistical significance or standardized effect estimates,

2 we considered more interpretable outcomes (Riedel et al., 2010) such as temporary

3 recovery from depression (i.e. remission), response to treatment ( $\geq 50 \%$ reduction in

4 depressive symptoms from baseline), and treatment acceptability or adherence (i.e.

5 drop-outs for any reason). Fourth, different from previous SRs, we assessed the risk of

6 bias of primary studies using tools that favor the identification of all potential sources of

7 bias (Sterne et al., 2019, 2016).

8

9 2. Methods

10 Our overview of SRs and meta-analyses of the effects of forest therapy on depression

11 was based on guidance from the latest edition of the Cochrane Handbook for Systematic

12 Reviews of Interventions (Higgins et al., 2019). We began the study by selecting SRs

13 most relevant to our research question centered on forest therapy and depression. We

14 located SRs by testing the utility of several databases (e.g., MEDLINE and PsycINFO)

15 and search terms such as forest therapy, forest bathing, and shinrin-yoku (see

16 Supplementary File p.1). Through this process, we found three SRs that met our criteria,

17 and a fourth was later identified via social media for researchers. However, if we were

18 to interpret only the results of these four SRs (rather than of the primary studies), we

19 would emerge with a limited answer to our research question. Thus, we decided to

20 analyze all eligible primary studies included by these four SRs. We did this by

21 developing our eligibility criteria (Table 1) and synthesis plan (see Supplementary File

22 p. 1 to 4) based on recent guidance from meta-analysis experts (e.g. Bender et al., 2018;

23 Higgins et al., 2019).

24 Regarding the eligibility criteria, we made important distinctions between forest

25 therapy, forest exposure, forest exercise, and forest walking. Forest exposure refers to 
1 be in a forest. Forest exercise involves doing physical exercise in a forest, which can

2 include walking. We operationalized forest therapy to include engagement in a

3 combination of forest-based activities to improve one's health or wellbeing. Thus,

4 forest-based exercise combined with other forest-based activities (e.g. meditation,

5 psychotherapy, group activities) met our definition of forest therapy. Nonetheless, just

6 being in a forest or exercising in a forest was not enough to satisfy this definition and

7 qualify as a forest therapy intervention for this study.

8

< Table 1 about here >

The first author of the present study collected relevant data from the four SRs, assessed the eligibility of primary studies (Table 1), gathered relevant data on eligible primary studies, and assessed the risk of bias of SRs and primary studies. All primary studies included in our meta-analyses were identified on the four SRs, so the first author screened primary studies for eligibility based on the information provided by the four SRs. Decisions regarding the eligibility of primary studies at full-text and their risk of bias assessment were checked by at least one co-author. Most information describing primary studies (e.g. sample size) was collected from the four SRs and then checked within the primary studies (Saldanha et al., 2019). The information used in our metaanalyses was extracted directly from primary studies. The first author checked the information from primary studies at least once after finishing the data extraction phase.

The risk of bias of the four SRs was assessed using the ROBIS tool (Whiting et al., 2016). The risk of bias of the primary studies was assessed using the RoB 2 for randomized controlled trials (RCTs) and cross-over trials (Sterne et al., 2019), and ROBINS-I for non-randomized controlled trials (NRCT) (Sterne et al., 2016). These are the most comprehensive tools available to assess potential bias in SRs, RCTs, crossovers, and NRCTs. Studies that assigned participants to groups based on a random or 
1 quasi-random process were classified as RCTs (Sterne et al., 2019). Studies that did not

2 describe the randomization process or assigned participants to interventions based on a

3 non-random criterion (e.g. participants' preference) were classified as NRCTs (Sterne et

4 al., 2016).

\section{2.1. Synthesizing Data from Primary Studies}

7 Following recommendations from the Cochrane Handbook, we focused on

8 results from RCTs and analyzed them separately from cross-overs trials, and NRCTs

9 (Higgins et al., 2019). Our main outcome was the standardized mean difference (SMD)

10 between the post-intervention depressive symptoms of two intervention groups.

11 Depressive symptoms scores are usually calculated by summing the score of items on a

12 depression rating scale for an individual. These items often cover a specific symptom

13 frequency and, sometimes, symptom intensity. The mean we used in our analysis was

14 the average score for the sample group in an intervention (e.g. the post-intervention

15 average score of the forest therapy group). When primary studies met all criteria needed

16 to be included in a meta-analysis (see Supplementary File p.1 to 2), we pooled their

17 SMDs because pooled SMDs are more precise than estimates of effect from single

18 studies (Higgins et al., 2019). Following Sawilowky (2009), we interpreted SMDs as:

19 very small $=0.01$, small $=0.2$, medium $=0.5$, large $=0.8$, very large $=1.2$, and huge $=$

$20 \quad 2.0$.

21 To improve the interpretability of the effect of forest therapy on depression

22 compared to other interventions, we also considered reductions in depressive symptoms

23 based on dichotomous outcomes such as remission from depression and response to

24 treatment (Riedel et al., 2010). Remission refers to a temporary recovery from

25 depression and is often assessed as "the number of patients with a score for depressive 
1 symptoms below a specific cut-off on a validated rating scale" (Cuijpers et al., 2020, p.

2 93). Response to treatment is usually registered as the number of people who exhibit $\geq$

$350 \%$ reduction of depressive symptoms from baseline following treatment. This

4 threshold is appropriate for the most commonly used scales to register depression: the

5 Hamilton Depression Rating Scale (HDRS or HAMD), Montgomery-Asberg

6 Depression Rating Scale (MADRS), and the Beck Depression Inventory (BDI), but

7 might not be appropriate for other scales (Riedel et al., 2010). None of the primary

8 studies we analyzed reported the number of people who responded to treatment (i.e.

9 responders). Thus, the number of responders in studies using one of these three scales

10 was estimated using the formula described by Furukawa et al. (2005). We do not report

11 the number of responders for primary studies that did not use one of these three scales.

12 We used drop-out for any reason as a proxy for treatment acceptability or adherence

13 (Cipriani et al., 2018; Cuijpers et al., 2020). For dichotomous outcomes, we calculated

14 risk ratios as they are easier to interpret than odds ratios (Higgins et al., 2019). We

15 reported the percentage of reduction in depressive symptoms from baseline in forest

16 therapy and comparison groups as a descriptive statistic (Vickers, 2001). We describe in

17 Equation 1 how this percentage was calculated. We also collected and reported

18 information about any adverse effects of forest therapy treatment described by primary

19 studies' authors.

((Post-intervention mean score - Baseline mean score)/Baseline mean score)*100 
1 primary studies were created using robvis (McGuinness, 2019). Data are publicly

2 available at: (inserting link when published).

3

\section{3. Results}

\section{$5 \quad 3.1$ Results of systematic reviews}

6 Selected characteristics (e.g. research question, eligibility criteria, search strategy, risk

7 of bias assessment, and main results) of the four SRs that we reviewed are described in

8 Supplementary File p. 6. By analyzing the eligibility criteria of these SRs, we noted that

9 they were not able to include: (1) unpublished studies; (2) studies in languages other

10 than English and Korean; (3) studies published after October 2019; and, (4) within

11 Korean studies: studies with children or adolescents ( $<18$ years old), without a

12 comparison group, or published after 2016.

13 The four SRs were deemed as at high risk of bias because of limitations that

14 could hinder the adequate identification, selection, data extraction, appraisal, or

15 synthesis of relevant primary studies (Table 2). For example, the synthesis methods

16 used in the four SRs conducted before our review were limited. Moreover, no SR

17 focused exclusively on the effect of forest therapy on depression. It is possible,

18 however, to extract some information about the effect of forest therapy on depression

19 because three of the four SRs reported results for each primary study. Djernis et al.'s

20 (2019) SR was the only one that did not report results for each primary study. Instead,

21 the authors provided, for example, a pooled estimate of the effect of forest activities on

22 a combination of psychological constructs. Kotera et al.'s (2020) SR provided estimates

23 of the effect of forest therapy on depression, but only for three of the 13 studies

24 analyzed in our study. The meta-analysis performed by Kotera et al. (2020) combined

25 results from measures of depression with results collected using a measure of mood 
1 state (the Profile of Mood States). More limiting, both Lee et al. (2017) and Wen et al.

2 (2019) used a vote-counting approach seemingly based on the statistical significance of

3 findings. While it is good to know if forest therapy is likely to have a positive effect on

4 depression, patients and practitioners also need to be aware of the magnitude of this

5 effect to make more informed decisions about the use/promotion of forest therapy.

6 11 four SRs described above.

12

\subsection{Results of primary studies}

< Table 2 about here >

Using primary studies, we built upon these SRs to provide more precise estimates of forest therapy's impact on depression relative to other alternatives such as no intervention/usual care or walking in a forest. The analyses presented in the next section are based on data extracted directly from primary studies that were part of the

The four SRs included a total of 101 primary studies. We eliminated 82 primary studies because they were duplicates or did not measure depression as defined in our eligibility criteria (Table 1). Nineteen studies were analyzed at full-text, of which six were eliminated (reasons for exclusion are provided in Fig. 1 and Supplementary Table 1 in the Supplementary File p. 4). Thus, 13 primary studies were included in our analyses (see Fig. 1 for a flow diagram and the Supplementary File p. 5 for the references of all included studies). Primary studies' characteristics are summarized in Table 3. All studies were conducted in the Republic of Korea (total number of participants $N=649$ ), and one of them included children. Most participants were older than 39 years old and the percentage of women across studies varied widely. Two studies were conducted with people suffering from major depression (Kim et al., 2009; Woo et al., 2012) and one study reported that most participants were depressed 
1 according to BDI and HDRS (Chun et al., 2017). The other 10 studies did not classify

2 their participants as depressed or non-depressed. However, considering established cut-

3 off points for diagnosing depression on the scales they used, the baseline mean scores of

4 these studies indicate that in eight of these 10 studies the average participant was

5 depressed. The two exceptions were Bang et al. (2018) and Hong (2012). Four studies

6 were RCTs, two were cross-overs, and seven were NRCTs. Most forest therapy

7 interventions involved meditation, physical activities, games, or group activities. Most

8 interventions took a few days or a few weeks, and no intervention was longer than 11

9 weeks. Across all studies, seven different measures of depression were used.

$<$ Fig. 1 about here>

<Table 3 about here>

Overall, we found support for the effectiveness of forest therapy in reducing depressive symptoms within RCTs, cross-over trials, and NRCTs with adults. For example, RCTs found on average a $60 \%$ reduction of depressive symptoms from baseline; the average on cross-over trials was $51 \%$ and $22 \%$ in NRCT (Table 4). Some studies provided more than one relevant comparison group, generating a total of five comparison groups (Table 5). These comparisons were: (1) forest therapy versus no intervention/usual care (including taking antidepressants as usual); (2) forest therapy versus similar activities in a hospital; (3) forest therapy versus similar activities in an urban area; (4) forest therapy versus diet plus exercise in a forest; and, (5) forest therapy versus walking in a forest. Below, we present results for each comparison.

\section{$<$ Table 4 and 5 about here>}

(1) Forest therapy versus no intervention/usual care: Three RCTs assessed this comparison. The SMD of post-intervention scores was similar in these studies and the polled estimate was large, favoring forest therapy (Heges' $g=1.18,95 \% C I[0.86,1.50]$, 
$1 \quad p<.00001$, Fig. 2a). Two of these three studies (Kim et al., 2009; Woo et al., 2012)

2 provided data for remission (operationalized as HRSD score $\leq 7$ ). In these two studies,

3 participants were taking antidepressants following their usual treatment; we refer to the

4 group that took only antidepressants as the usual care for depression group. Participants

5 in the forest groups were 17 times as likely to achieve remission compared to

6 participants in the usual care for depression group (Risk Ratio $=17.02,95 \%$ CI [3.40,

$785.21], p=.0006$, Fig. 2b). Also, participants in the forest groups were three times as

8 likely to respond to treatment (Risk Ratio $=3.18,95 \% C I[1.94,5.21], p<.00001$, Fig.

9 2c). The pooled SMD of NRCTs was similar to that of RCTs (Supplementary Fig. 1 in

10 the Supplementary File p. 7). The pooled results of two NRCTs that used the BDI scale

11 indicated that response to treatment was more likely to occur in the forest group, but

12 these results are inconclusive (Risk Ratio $=1.43,95 \%$ CI $[0.78,2.62], p=.26$, see

13 Supplementary Fig. 2 in the Supplementary File p. 7).

< Fig. 2 about here >

Only one study focused on depression in children. This study assessed the

16 comparison between forest therapy and no intervention/usual care. In Bang et al. (2018),

17 there is a considerable imbalance in the baseline depressive symptoms between the

18 forest group $($ mean $=12.26)$ and the no intervention group $($ mean $=9.39)$, and an

19 appropriate method to account for this imbalance was not used. For example, by using

20 ANCOVA the researchers could have compared the post-test scores while keeping the

21 baseline score statistically constant (Higgins et al., 2019). Thus, we calculated the mean

22 change from baseline for each group and its standard deviation based on the available

23 results. The mean reduction in depressive symptoms from baseline was greater in the

24 forest therapy group than in the no intervention group, but results are inconclusive

25 (Hedges' $g=0.29,95 \%$ CI [-0.26, 0.83, $], p=.31$ ). 
(2) Forest therapy versus similar activities in a hospital: Two RCTs assessed

2 this comparison (Kim et al., 2009; Woo et al., 2012). In these RCTs, one group engaged

3 in forest therapy and the other group performed similar activities to the forest therapy

4 group but in a hospital. The pooled SMD of the post-intervention scores of the forest

5 therapy group and the hospital group was medium, favoring forest therapy (Hedges' $g=$

$6 \quad 0.63,95 \%$ CI [0.20, 1.06,], $p=.004$, Fig. 3a). These studies also reported results for

7 remission (operationalized as HDRS score $\leq 7$ ). Participants in the forest group were

8 two times as likely to achieve remission as participants in the hospital group (Risk Ratio

$9=1.97,95 \% C I[1.22,3.21], p=.006$, Fig. 3b). Participants in the forest group were also

10 more likely to respond to treatment (Risk Ratio $=1.69,95 \%$ CI $[0.98,2.91], p=.06$,

11 Fig. 3c). One NRCT assessed this comparison (Lim et al., 2014) and found results

12 similar to the ones of RCTs (Hedges' $g=0.76,95 \%$ CI [0.14, 1.38, $], p=.02$ ).

< Fig. 3 about here >

(3) Forest therapy versus similar activities in an urban area: A RCT conducted

with chronic stroke patients compared forest therapy with similar activities done in an

urban environment (Chun et al., 2017). This study found a huge difference between groups' post-intervention scores, favoring forest therapy (Hedges' $g=2.60,95 \% C I$

$[1.89,3.30],, p<.00001)$. Participants in the forest group were 13 times as likely to respond to treatment compared to participants in the urban group (Risk Ratio $=13.05$, $95 \%$ CI [3.41, 49.97], $p=.0002)$.

(4) Forest therapy versus diet plus forest-based exercise: Two cross-over trials assessed this comparison and measured depression using the BDI. The diet plus exercise phase of the trial occurred first. After 28 days (the washout period) the forest therapy phase took place. Hong et al. (2012) found that the forest therapy phase reduced participants' depressive symptoms more than the diet plus forest-based exercise phase 
1 (reduction on BDI score $=-12.76,95 \% C I[-18.82,-6.70], p=.0001$, Cohen's $d=1.03$ ).

2 Hong et al. (2013) found similar results (reduction on BDI score $=-4.48,95 \%$ CI [-8.09,

3 -0.87], $p=.01$, Cohen's $d=0.61$ ). We were unable to calculate a Hedges' $g$ and the

4 dispersion of the SMDs because these studies did not report the correlation between

5 individuals' outcome data between the two phases of the trial. A pooled risk ratio

6 indicated that, during the forest therapy phase, participants were more likely to respond

7 to treatment than during the diet plus forest-based exercise phase (Risk Ratio $=3.20$,

$895 \%$ CI [1.33, 7.68], $p=.009$, see Supplementary Fig. 3 in the Supplementary file p. 7).

(5) Forest therapy versus walking in a forest: One RCT assessed this

10 comparison (Woo et al., 2012). There was a substantial imbalance in the baseline values

11 of the forest therapy group $($ mean $=24.21)$ and the walking in forest group $($ mean $=$

12 18.47), and an appropriate method to account for this imbalance was not used for this

13 comparison (e.g. ANCOVA). We were unable to calculate a standard deviation for the

14 mean change from baseline, so we only report descriptive statistics and differences in

15 the likelihood of response to treatment. The forest therapy group had a reduction of 50\%

16 in the baseline symptoms and the walking in a forest group a reduction of $32 \%$.

17 Participants in the forest therapy group were more likely to respond to treatment, but

18 results are inconclusive (Risk Ratio $=1.25,95 \%$ CI $[0.61,2.57], p=.54)$.

19 Finally, we conducted sensitivity analyses to test the robustness of some

20 decisions taken during the synthesis process (Supplementary File p. 8 to 9). These

21 analyses suggest that our findings are robust to these decisions.

3.2.1 Treatment acceptability and adverse effects

Most studies did not provide a flow diagram showing how many participants

25 were assigned to each group and how many participants finished the study. Thus, the 
1 use of participant drop-outs as a proxy for treatment acceptability was not optimal.

2 Nevertheless, drop-outs were documented in six studies. In these studies, the number of

3 drop-outs for any reason was scarce, and there was no evidence of differences between

4 intervention groups (Supplementary Fig. 4 in Supplementary File p. 8). Eleven of 13

5 studies did not present any information about adverse effects (i.e. if they occurred or if

6 they did not occur). Only two studies reported information about the (no) occurrence of

7 adverse effects. In one study, a participant developed a rash caused by an insect bite in

8 the forest (Kim et al., 2009); in the other study, the authors noted that participants

9 reported no health problems during the forest therapy intervention (Choi and Ha, 2014).

10 Thus, from a total of 311 people involved in forest therapy, in the 13 primary studies

11 that we analyzed, only one $(0.3 \%)$ had an adverse effect reported.

13 3.2.2 Risk of bias of primary studies, publication bias, and statistical heterogeneity

14 We deemed all RCTs and cross-over trials as at high risk of bias (Supplementary

15 File p. 10) and the NRCTs as at serious risk of bias (Supplementary File p. 12). When

16 assessing RCTs, cross-overs, and NRCTs, we followed the recommendations of the

17 tools' developers to determine the risk of bias for each domain and overall for a specific

18 result of each study (Sterne et al., 2019, 2016). Additional information about the risk of

19 bias assessment is provided in the Supplementary File p. 9 to 12.

20 Due to the small number of studies included in our meta-analyses, it was not

21 appropriate to test for publication bias (i.e. if results from unpublished studies are

22 different from the results of published studies; Higgins et al., 2019). For instance, one of

23 the statistical requirements for using funnel plots to assess publication bias is to include

2410 or more studies in a specific meta-analysis (Higgins et al., 2019). 
Only one of the meta-analyses we conducted (Supplementary Fig. 1 in

2 Supplementary File p. 7) produced substantial statistical heterogeneity, but we did not

3 try to explain this heterogeneity (e.g. using meta-regression) due to the small number of

4 studies included in this meta-analysis (Higgins et al., 2019).

\section{4. Discussion}

. In the present study, we analyzed four recent SRs that explored connections

between forest therapy and depression, focusing on forest therapy's capacity to reduce

9 depressive symptoms in comparison to no intervention/usual care and four alternative

10 interventions. Our findings show the effect of forest therapy on depression is greater

11 than the effect of any alternative intervention. People in forest therapy groups had a

12 higher reduction in depressive symptoms than people in the other groups.

When compared to similar interventions in non-forest settings, the benefits of

15 forest therapy were clear. Being involved in therapeutic activities in a forest appears to

16 be more effective than participating in such activities in a hospital or in an urban (non-

17 forested) area. Assuming the only difference between the forest therapy group and the

18 other groups was the intervention setting, these findings suggest that exposure to a

19 forest environment may provide additional benefits beyond the therapeutic activities

20 themselves. This is in line with research showing the benefits of exposure to nature, and

21 forests specifically (Wen et al., 2019; Wolf et al., 2020). For example, Bowler et al.

22 (2010) conducted meta-analyses of studies comparing the effect of the same activity

23 conducted in a natural versus a synthetic environment. They found that individuals who

24 conducted the activities in natural environments expressed less anger, fatigue, and

25 sadness than individuals in synthetic environments. Our results are also in line with 
1 research conducted under stress reduction theory (Ulrich et al., 1991) and attention

2 restoration theory (Kaplan, 1995), which have consistently shown that exposure to

3 natural environments favors stress reduction, mood improvement, and the recovery of

4 attentional capabilities more than non-natural environments.

Our findings also revealed that forest therapy was more effective than depression

6 treatment regimens focused on diet plus forest-based exercise. Whereas diet, exercise,

7 and forest exposure may reduce depressive symptoms, the greater effect of forest

8 therapy on depression may be explained by the activities in which the forest therapy

9 groups participated (Djernis et al., 2019; Kim et al., 2009). The distinction between

10 forest therapy (a combination of activities positive for mental health) and forest exercise

11 is important. Whereas green exercise can yield a variety of positive health outcomes

12 (Bowler et al., 2010; Gladwell et al., 2013), forest therapy, which includes other

13 activities positive for mental health, may be more effective to prevent and treat

14 depression. Similar conclusions can be drawn for the comparison between forest

15 therapy and walking in a forest, as the forest therapy group generally had a higher

16 reduction in depressive symptoms and greater response to treatment than the forest

17 walking group (although the confidence interval for the estimate of the difference

18 between these interventions overlaps zero).

19 Analyzing the number of drop-outs in the intervention groups across the studies

20 synthesized, we found no evidence that forest therapy was a less acceptable treatment

21 than other alternatives (Supplementary Fig. 4 in the Supplementary File p. 8). We also

22 found that the adverse effects of forest therapy may be rare. 
Several limitations should be considered when interpreting the results of our

2 study. First, we selected only four relevant SRs. Nonetheless, as the last SR we included

3 (Kotera et al., 2020) did not provide any new primary study, it seems that our approach

4 was sufficiently comprehensive. Also supporting this view, no new eligible primary

5 study was found in a recently published SR about the effect of forest activities on

6 physiological and psychological outcomes (Rajoo et al., 2020).

Second, the screening process of primary studies and subsequent data extraction

8 was not checked by another reviewer. We judged that it was not necessary to have

9 another reviewer involved in the screening because this process was relatively simple.

10 Regarding data extraction, the first author checked the information describing primary

11 studies and information used in meta-analyses at least once after finishing the data

12 extraction phase.

13 Third, although the findings from our meta-analyses are encouraging and

14 underscore the potential of forest therapy to prevent and treat depression, we should

15 interpret these findings with some caution due to the limitations of existing primary

16 studies. Overall, the primary studies included a considerable diversity of participants

17 (e.g. health and unhealthy people), interventions, comparison groups, outcome

18 measures, and settings. Nonetheless, young adults were underrepresented, as the mean

19 age/age range of adults was above 39 years and only one study included children (and it

20 yielded inconclusive results). Thus, it remains unclear if the effect of forest therapy on

21 depression is higher or lower on children, adolescents, and young adults.

22 Fourth, caution should also be executed when interpreting our results because all

23 the studies included in our review were conducted in the Republic of Korea, as these

24 were the only studies we located from anywhere in the world that evaluated forest

25 therapy interventions and reported results for depression outcome measures. 
1 Considering that forest activities are popular elsewhere in Asia (Yu and Hsieh, 2020),

2 future research could systematically search for primary studies conducted in countries

3 such as Japan and Taiwan. This also highlights the need for wider geographic coverage

4 in research about the forest therapy effect on depression.

Fifth, our inability to incorporate unpublished research also casts some doubt

6 about the true effectiveness of forest therapy, as there is evidence that studies are more

7 likely to be published if they reveal statistically significant treatment effects (Higgins et

8 al., 2019). Although the effect of forest therapy might have been overestimated (or

9 underestimated), the publication of forest therapy findings is unlikely to be heavily

10 influenced by financial interests, which favor the publication of positive results, as is the

11 case for antidepressant studies (Munkholm et al., 2019). We examined the reported

12 funding and conflict of interest of primary studies and found no evidence of any conflict

13 of interest.

14 Finally, methodological limitations of the primary studies in our analyses

15 increase uncertainty about the true effect of forest therapy on depression. Only four

16 RCTs and two cross-over trials were included in our meta-analyses, and all had a high

17 risk of bias. The main limitations of these studies were the lack of blinding, which is

18 infeasible in forest therapy interventions because people experience the treatment

19 environment, and the lack of a protocol describing the analysis plan. The former

20 increases the risk of deviations from the intended intervention and can introduce bias in

21 the assessment of treatment-related outcomes. The latter hinders the possibility of

22 assessing selective reporting. Limitations were also identified in the randomization

23 process and in the way some studies dealt with missing outcome data. Whereas most of

24 these limitations are typically associated with an exaggeration of experimental

25 intervention effects (in our case, forest therapy), in some circumstances the effect can be 
1 underestimated (Sterne et al., 2019, 2016). Moreover, a NRCT was the only source of

2 evidence for the impact of forest therapy on children's depressive symptoms, and other

3 NRCTs provided additional information for two comparisons (i.e. forest therapy versus

4 no intervention/usual care, and forest therapy versus similar activities in a hospital).

5 Similar to RCTs and crossover trials, the NRCTs were not blinded and did not publish

6 an analysis plan. Besides these limitations, NRCTs tend to have a higher risk of bias

7 than RCTs due to confounding, as the assignment of participants to the intervention can

8 be related to baseline variables that influence the outcome (i.e. prognostic factors).

\section{$10 \quad$ 5. Future research opportunities and conclusions}

In summary, future literature reviews may extend the evidence we have

synthesized by systematically searching for unpublished studies, studies in other languages than English and Korean, and studies with children and adolescents. Future primary studies should document if (and what) adverse effects occurred in the forest therapy and comparison group(s) and report remission from depression and response to treatment. Future research could also examine whether certain aspects of forest therapy (e.g., meditation vs. green exercise) are more beneficial than others when it comes to treating depression. It includes assessing if or how different frequency and duration of forest therapy interventions may influence the reduction in depressive symptoms. The adoption of relevant Consolidated Standards of Reporting Trials (CONSORT) should

21 facilitate the assessment of primary studies' risk of bias and the interpretation of their

22 results (Moher et al., 2010). Our findings also highlight the need for more methodologically rigorous RCTs examining the effects of forest therapy on depression. Despite some limitations, our review of SRs and primary studies examining the 
1 yielded the most conclusive evidence to date. Compared to antidepressants, similar

2 activities in a hospital or non-forested urban settings, or even diet and forest-based

3 exercise, forest therapy appears to be more likely to produce outcomes like remission

4 and response to treatment, with adequate acceptability or adherence. Thus, while more

5 studies are needed, we believe practitioners should consider the use of forest therapy as

6 both a preventive measure and a treatment for depression in adults. This is in line with

7 the growing support for the incorporation of therapeutical activities in contact with

8 nature as a mainstream intervention for the prevention and treatment of mental health

9 problems (Buckley et al., 2018).

11 References

12 Bang, K.-S., Kim, S., Song, M., Kang, K., Jeong, Y., 2018. The effects of a health

13 promotion program using urban forests and nursing student mentors on the

14 perceived and psychological health of elementary school children in vulnerable

15 populations. Int. J. Environ. Res. Public Health 15.

16 https://doi.org/10.3390/ijerph15091977

17 Bender, R., Friede, T., Koch, A., Kuss, O., Schlattmann, P., Schwarzer, G., Skipka, G., 18 2018. Methods for evidence synthesis in the case of very few studies. Res. Synth. 19 Methods. https://doi.org/10.1002/jrsm.1297

20 Bowler, D.E., Buyung-Ali, L.M., Knight, T.M., Pullin, A.S., 2010. A systematic review 21 of evidence for the added benefits to health of exposure to natural environments. BMC Public Health 10, 456. https://doi.org/10.1186/1471-2458-10-456

Bratman, G.N., Anderson, C.B., Berman, M.G., Cochran, B., de Vries, S., Flanders, J., 24 Folke, C., Frumkin, H., Gross, J.J., Hartig, T., Kahn, P.H., Kuo, M., Lawler, J.J., Levin, P.S., Lindahl, T., Meyer-Lindenberg, A., Mitchell, R., Ouyang, Z., Roe, J., 
Scarlett, L., Smith, J.R., van den Bosch, M., Wheeler, B.W., White, M.P., Zheng, H., Daily, G.C., 2019. Nature and mental health: An ecosystem service perspective. Sci. Adv. 5, eaax0903. https://doi.org/10.1126/sciadv.aax0903

Buckley, R.C., Brough, P., Westaway, D., 2018. Bringing outdoor therapies into mainstream mental health. Front. Public Heal. 6. https://doi.org/10.3389/fpubh.2018.00119

Carvalho, A.F., Sharma, M.S., Brunoni, A.R., Vieta, E., Fava, G.A., 2016. The safety, tolerability and risks associated with the use of newer generation antidepressant drugs: A critical review of the literature. Psychother. Psychosom. 85, 270-288. https://doi.org/10.1159/000447034

Choi, Y.H., Ha, Y.S., 2014. The effectiveness of a forest-experience-integration intervention for community dwelling cancer patients' depression and resilience. J. Korean Acad. Community Heal. Nurs. 25, 109. https://doi.org/10.12799/jkachn.2014.25.2.109

Chun, M.H., Chang, M.C., Lee, S.-J., 2017. The effects of forest therapy on depression and anxiety in patients with chronic stroke. Int. J. Neurosci. 127, 199-203. https://doi.org/10.3109/00207454.2016.1170015

Cipriani, A., Furukawa, T.A., Salanti, G., Chaimani, A., Atkinson, L.Z., Ogawa, Y., Leucht, S., Ruhe, H.G., Turner, E.H., Higgins, J.P.T., Egger, M., Takeshima, N., Hayasaka, Y., Imai, H., Shinohara, K., Tajika, A., Ioannidis, J.P.A., Geddes, J.R., 2018. Comparative efficacy and acceptability of 21 antidepressant drugs for the acute treatment of adults with major depressive disorder: A systematic review and network meta-analysis. Lancet 391, 1357-1366. https://doi.org/10.1016/S01406736(17)32802-7

Collado, S., Staats, H., Corraliza, J.A., Hartig, T., 2017. Restorative environments and 
health, in: Navarro, O., Fleury-Bahi, G., Pol, E. (Eds.), Handbook of

Environmental Psychology and Quality of Life Research. Springer, New York, pp.

127-148. https://doi.org/10.1007/978-3-319-31416-7_7

Cuijpers, P., 2018. The challenges of improving treatments for depression. JAMA 320, 2529-2530. https://doi.org/10.1001/jama.2018.17824

Cuijpers, P., Noma, H., Karyotaki, E., Vinkers, C.H., Cipriani, A., Furukawa, T.A., 2020. A network meta- analysis of the effects of psychotherapies,

pharmacotherapies and their combination in the treatment of adult depression.

World Psychiatry 19, 92-107. https://doi.org/10.1002/wps.20701

Djernis, Lerstrup, Poulsen, Stigsdotter, Dahlgaard, O’Toole, 2019. A Systematic review

1 and meta-analysis of nature-based mindfulness: effects of moving mindfulness

training into an outdoor natural setting. Int. J. Environ. Res. Public Health 16, 3202. https://doi.org/10.3390/ijerph16173202

Fried, E.I., 2017. The 52 symptoms of major depression: Lack of content overlap

5 among seven common depression scales. J. Affect. Disord. 208, 191-197.

https://doi.org/10.1016/j.jad.2016.10.019

Furukawa, T.A., Cipriani, A., Barbui, C., Brambilla, P., Watanabe, N., 2005. Imputing 8 response rates from means and standard deviations in meta-analyses. Int. Clin. 9 Psychopharmacol. 20, 49-52. https://doi.org/10.1097/00004850-200501000-00010

Gladwell, V.F., Brown, D.K., Wood, C., Sandercock, G.R., Barton, J.L., 2013. The 1 great outdoors: How a green exercise environment can benefit all. Extrem. Physiol. 22 Med. 2, 1-7. https://doi.org/10.1186/2046-7648-2-3

3 Han, J.-W., Choi, H., Jeon, Y.-H., Yoon, C.-H., Woo, J.-M., Kim, W., 2016. The

4 Effects of Forest Therapy on Coping with Chronic Widespread Pain: Physiological 25 and Psychological Differences between Participants in a Forest Therapy Program 
and a Control Group. Int. J. Environ. Res. Public Health 13. https://doi.org/10.3390/ijerph13030255

Hansen, M.M., Jones, R., Tocchini, K., 2017. Shinrin-yoku (forest bathing) and nature therapy: A state-of-the-art review. Int. J. Environ. Res. Public Health 14. https://doi.org/10.3390/ijerph14080851

Higgins, J.P.T., Thomas, J., Chandler, J., Cumpston, M., Li, T., Page, M.J., Welch, V.A. (Eds.), 2019. Cochrane Handbook for Systematic Reviews of Interventions, 2nd ed. John Wiley \& Sons, Chichester.

Hong, S.-S., Kim, H.-C., Cho, S.-H., 2013. The Effects of Forests Healing for Cognitive Function. J. Orient. Neuropsychiatry 24, 63-74. https://doi.org/10.7231/jon.2013.24.1.063

Hong, S.-S., Lee, J.-E., Kim, H.-C., Cho, S.-H., 2012. The Effects of Forests Healing for Hwa-Byung. J. Orient. Neuropsychiatry 23, 169-182. https://doi.org/10.7231/jon.2012.23.4.169

Kaplan, S., 1995. The restorative benefits of nature: Toward an integrative framework. J. Environ. Psychol. 15, 169-182. https://doi.org/10.1016/0272-4944(95)90001-2

Kim, W., Lim, S.-K., Chung, E.-J., Woo, J.-M., 2009. The effect of cognitive behavior therapy-based psychotherapy applied in a forest environment on physiological changes and remission of major depressive disorder. Psychiatry Investig. 6, 245. https://doi.org/10.4306/pi.2009.6.4.245

Kotera, Y., Richardson, M., Sheffield, D., 2020. Effects of Shinrin-Yoku (Forest Bathing) and Nature Therapy on Mental Health: A Systematic Review and MetaAnalysis.

Lee, I., Choi, H., Bang, K.-S., Kim, S., Song, M., Lee, B., 2017. Effects of forest therapy on depressive symptoms among adults: A systematic review. Int. J. 
Environ. Res. Public Health 14. https://doi.org/10.3390/ijerph14030321

2 Lim, Y., Kim, D., Yeoun, P., 2014. Changes in depression degree and self-esteem of senior sitizens in a nursing home according to forest therapy program. J. Korean Inst. For. Recreat. 18, 1-11. https://doi.org/10.34272/forest.2014.18.1.001

Lopresti, A.L., 2019. It is time to investigate integrative approaches to enhance treatment outcomes for depression? Med. Hypotheses 126, 82-94.

https://doi.org/10.1016/j.mehy.2019.03.008

Mayer, F.S., Frantz, C.M.P., Bruehlman-Senecal, E., Dolliver, K., 2009. Why is nature

beneficial? The role of connectedness to nature. Environ. Behav. 41, 607-643.

https://doi.org/10.1177/0013916508319745

McGuinness, L., 2019. robvis: An R package and web application for visualising riskof-bias assessments.

Moher, D., Hopewell, S., Schulz, K.F., Montori, V., Gøtzsche, P.C., Devereaux, P.J., Elbourne, D., Egger, M., Altman, D.G., 2010. CONSORT 2010 explanation and elaboration: Updated guidelines for reporting parallel group randomised trials. Int.

J. Surg. 10, 28-55. https://doi.org/https://doi.org/10.1136/bmj.c869

Munkholm, K., Paludan-Müller, A.S., Boesen, K., 2019. Considering the methodological limitations in the evidence base of antidepressants for depression: A reanalysis of a network meta-analysis. BMJ Open 9, e024886. https://doi.org/10.1136/bmjopen-2018-024886

Nordgaard, J., Sass, L.A., Parnas, J., 2013. The psychiatric interview: Validity, structure, and subjectivity. Eur. Arch. Psychiatry Clin. Neurosci. 263, 353-364. https://doi.org/10.1007/s00406-012-0366-z

Oh, B., Lee, K.J., Zaslawski, C., Yeung, A., Rosenthal, D., Larkey, L., Back, M., 2017. Health and well-being benefits of spending time in forests: systematic review. 
Environ. Health Prev. Med. 22. https://doi.org/10.1186/s12199-017-0677-9

2 Park, B.J., Tsunetsugu, Y., Kasetani, T., Kagawa, T., Miyazaki, Y., 2010. The physiological effects of Shinrin-yoku (taking in the forest atmosphere or forest bathing): evidence from field experiments in 24 forests across Japan. Environ. Health Prev. Med. 15, 18-26. https://doi.org/10.1007/s12199-009-0086-9

Rajoo, K.S., Karam, D.S., Abdul Aziz, N.A., 2019. Developing an effective forest therapy program to manage academic stress in conservative societies: A multidisciplinary approach. Urban For. Urban Green. 43, 126353.

Rajoo, K.S., Karam, D.S., Abdullah, M.Z., 2020. The physiological and psychosocial effects of forest therapy: A systematic review. Urban For. Urban Green. 126744.

Review Manager (RevMan) [Computer program], 2014.

Riedel, M., Möller, H.-J., Obermeier, M., Schennach-Wolff, R., Bauer, M., Adli, M., Kronmüller, K., Nickel, T., Brieger, P., Laux, G., Bender, W., Heuser, I., Zeiler, J.,

Saldanha, I.J., Smith, B.T., Ntzani, E., Jap, J., Balk, E.M., Lau, J., 2019. The Systematic Gaebel, W., Seemüller, F., 2010. Response and remission criteria in major depression - A validation of current practice. J. Psychiatr. Res. 44, 1063-1068. https://doi.org/10.1016/j.jpsychires.2010.03.006

Sawilowsky, S.S., 2009. New effect size rules of thumb. J. Mod. Appl. Stat. Methods 8, 597-599. https://doi.org/10.22237/jmasm/1257035100

25 Sterne, J.A., Hernán, M.A., Reeves, B.C., Savović, J., Berkman, N.D., Viswanathan, 
M., Henry, D., Altman, D.G., Ansari, M.T., Boutron, I., Carpenter, J.R., Chan, A.W., Churchill, R., Deeks, J.J., Hróbjartsson, A., Kirkham, J., Jüni, P., Loke, Y.K., Pigott, T.D., Ramsay, C.R., Regidor, D., Rothstein, H.R., Sandhu, L., Santaguida, P.L., Schünemann, H.J., Shea, B., Shrier, I., Tugwell, P., Turner, L., Valentine, J.C., Waddington, H., Waters, E., Wells, G.A., Whiting, P.F., Higgins, J.P., 2016. ROBINS-I: a tool for assessing risk of bias in non-randomised studies of interventions. BMJ. https://doi.org/10.1136/bmj.i4919

Sterne, J.A., Savović, J., Page, M.J., Elbers, R.G., Blencowe, N.S., Boutron, I., Cates, C.J., Cheng, H.-Y., Corbett, M.S., Eldridge, S.M., Emberson, J.R., Hernán, M.A., Hopewell, S., Hróbjartsson, A., Junqueira, D.R., Jüni, P., Kirkham, J.J., Lasserson, T., Li, T., McAleenan, A., Reeves, B.C., Shepperd, S., Shrier, I., Stewart, L.A., Tilling, K., White, I.R., Whiting, P.F., Higgins, J.P.T., 2019. RoB 2: a revised tool for assessing risk of bias in randomised trials. BMJ 14898. https://doi.org/10.1136/bmj.14898

Ulrich, R.S., Simons, R.F., Losito, B.D., Fiorito, E., Miles, M.A., Zelson, M., 1991. Stress recovery during exposure to natural and urban environments. J. Environ. Psychol. 11, 201-230. https://doi.org/10.1016/S0272-4944(05)80184-7

van de Leemput, I.A., Wichers, M., Cramer, A.O.J., Borsboom, D., Tuerlinckx, F., Kuppens, P., van Nes, E.H., Viechtbauer, W., Giltay, E.J., Aggen, S.H., Derom, C., Jacobs, N., Kendler, K.S., van der Maas, H.L.J., Neale, M.C., Peeters, F., Thiery, E., Zachar, P., Scheffer, M., 2014. Critical slowing down as early warning for the onset and termination of depression. Proc. Natl. Acad. Sci. 111, 87-92. https://doi.org/10.1073/pnas.1312114110

van Tulleken, C., Tipton, M., Massey, H., Harper, C.M., 2018. Open water swimming as a treatment for major depressive disorder. BMJ Case Rep. 
https://doi.org/10.1136/bcr-2018-225007

2 Vickers, A.J., 2001. The use of percentage change from baseline as an outcome in a controlled trial is statistically inefficient: A simulation study. BMC Med. Res. Methodol. 1, 6. https://doi.org/10.1186/1471-2288-1-6

Wen, Y., Yan, Q., Pan, Y., Gu, X., Liu, Y., 2019. Medical empirical research on forest bathing (Shinrin-yoku): A systematic review. Environ. Health Prev. Med. 24, 70. https://doi.org/10.1186/s12199-019-0822-8

Whiting, P., Savović, J., Higgins, J.P.T., Caldwell, D.M., Reeves, B.C., Shea, B., Davies, P., Kleijnen, J., Churchill, R., 2016. ROBIS: A new tool to assess risk of bias in systematic reviews was developed. J. Clin. Epidemiol. 69, 225-234.

Wolf, K.L., Lam, S.T., McKeen, J.K., Richardson, G.R.A., van den Bosch, M., Bardekjian, A.C., 2020. Urban trees and human health: A scoping review. Int. J. Environ. Res. Public Health 17. https://doi.org/10.3390/ijerph17124371

Woo, J.M., Park, S.M., Lim, S.K., Kim, W., 2012. Synergistic Effect of Forest Environment and Therapeutic Program for the Treatment of Depression. J. Korean Soc. For. Sci. 101, 677-685.

World Health Organization, 2017. Depression and other common mental disorders: Global health estimates. of forest therapy on creativity. Urban For. Urban Green. 51, 126670. https://doi.org/10.1016/j.ufug.2020.126670 
1 Table 1. Eligibility criteria for our overview of systematic reviews examining links

2 between forest therapy and depression based on participants (P), intervention (I),

3 comparator (C), outcome (O), and setting (S) (i.e. PICOS)

\begin{tabular}{|c|c|c|}
\hline $\begin{array}{l}\text { PICOS } \\
\text { element }\end{array}$ & Inclusion criteria & Exclusion criteria \\
\hline Participants & Studies with humans, healthy or not. & $\begin{array}{l}\text { Studies not including } \\
\text { humans. }\end{array}$ \\
\hline Intervention & $\begin{array}{l}\text { Studies reporting any intervention that } \\
\text { matched our definition of forest therapy, which } \\
\text { we defined as engaging in a combination of } \\
\text { activities in a forest to improve one's health or } \\
\text { wellbeing. Moreover, in our definition, a forest } \\
\text { therapy intervention should include more than } \\
\text { just exposure to nature or exercising in a } \\
\text { forest, incorporating other activities positive } \\
\text { for mental health (e.g. meditation and group } \\
\text { activities). }\end{array}$ & $\begin{array}{l}\text { Studies that only involved } \\
\text { exposure to nature or } \\
\text { exercising in a forest. }\end{array}$ \\
\hline Comparator & $\begin{array}{l}\text { Studies with any comparison group and studies } \\
\text { without a comparison group. }\end{array}$ & NA \\
\hline Outcome & $\begin{array}{l}\text { Studies where depression was estimated by } \\
\text { clinical examination (e.g. by a physician) or by } \\
\text { a previously developed (not } a d \text { hoc) } \\
\text { instrument (e.g. questionnaire or standardized } \\
\text { interview such as the DSM-IV) designed to } \\
\text { diagnose or estimate the intensity of this } \\
\text { disorder. }\end{array}$ & $\begin{array}{l}\text { Studies that assessed specific } \\
\text { depressive symptoms in } \\
\text { isolation (e.g. mood or } \\
\text { anxiety). }\end{array}$ \\
\hline Setting & $\begin{array}{l}\text { Studies of environments that primary study } \\
\text { authors described as a forest (e.g. urban-forest, } \\
\text { campus forest, recreational forest). }\end{array}$ & $\begin{array}{l}\text { Studies not describing a } \\
\text { forest. }\end{array}$ \\
\hline
\end{tabular}


1 Table 2. Risk of bias assessment of the systematic reviews included in our overview

\begin{tabular}{|c|c|c|c|c|c|}
\hline \multirow{2}{*}{$\begin{array}{c}\text { Systematic } \\
\text { Review }\end{array}$} & \multicolumn{4}{|c|}{ Risk of bias in specific domains } & \multirow{2}{*}{\begin{tabular}{l}
\multicolumn{1}{c}{ Overall } \\
Risk of Bias in \\
the Review
\end{tabular}} \\
\hline & $\begin{array}{l}\text { 1. Study } \\
\text { Eligibility } \\
\text { Criteria }\end{array}$ & $\begin{array}{l}\text { 2. Identification and } \\
\text { Selection of Studies }\end{array}$ & $\begin{array}{l}\text { 3. Data Collection } \\
\text { and Study } \\
\text { Appraisal }\end{array}$ & $\begin{array}{l}\text { 4. Synthesis } \\
\text { and Findings }\end{array}$ & \\
\hline $\begin{array}{l}\text { (Lee et al., } \\
2017)\end{array}$ & :: & : & :: & : : & : \\
\hline $\begin{array}{l}\text { (Wen et al., } \\
\text { 2019) }\end{array}$ & (:) & : & ;) & : & : \\
\hline $\begin{array}{l}\text { (Djernis et } \\
\text { al., 2019) }\end{array}$ & : & ;) & : & : & : \\
\hline $\begin{array}{l}\text { (Kotera et } \\
\text { al., 2020) }\end{array}$ & : & : & : & : & : \\
\hline
\end{tabular}

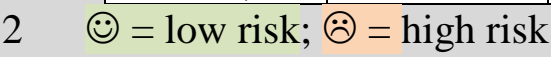

3 Note. Systematic reviews' risk of bias was assessed using ROBIS (Whiting et al., 2016),

4 a tool specially designed for this function. As recommended by ROBIS's developers,

5 we classified the risk of bias for each systematic review domain (eligibility criteria,

6 search strategy and selection, data collection and primary studies appraisal, and

7 synthesis and findings) and the systematic review as a whole. 
Table 3. Main characteristics of primary studies included in our meta-analyses examining links between forest therapy and depression

\begin{tabular}{|c|c|c|c|c|c|c|c|c|c|c|c|c|}
\hline $\begin{array}{c}\text { First } \\
\text { author } \\
\text { and year }\end{array}$ & Participants & $\begin{array}{l}\text { Mean } \\
\text { age or } \\
\text { range }\end{array}$ & $\begin{array}{c}\text { Women } \\
\%\end{array}$ & Forest therapy group/activities & $\begin{array}{l}\begin{array}{l}\text { Forest } \\
\text { therapy } \\
\text { duration }\end{array} \\
\end{array}$ & $\begin{array}{l}\text { Forest therapy } \\
\text { frequency }\end{array}$ & $\begin{array}{c}\begin{array}{c}\text { Forest } \\
\text { therapy } \\
N\end{array} \\
\text {. }\end{array}$ & $\begin{array}{c}\text { Comparison } \\
\text { group/activities }\end{array}$ & $\begin{array}{l}\text { Depression } \\
\text { measure* }\end{array}$ & Study design & Setting & $\begin{array}{l}\text { Data collection } \\
\text { framework }\end{array}$ \\
\hline Han 2016 & $\begin{array}{l}\text { Office workers } \\
\text { from the } \\
\text { University of } \\
\text { Seoul }\end{array}$ & 39.75 & 57.4 & $\begin{array}{l}\text { The intervention included walking } \\
\text { and mindfulness meditation. }\end{array}$ & $\begin{array}{l}\text { Two days } \\
\text { (noon to } \\
\text { noon) }\end{array}$ & All days & 33 & $\begin{array}{l}(N=28) \text { Normal daily } \\
\text { routines }\end{array}$ & BDI & $\begin{array}{l}\text { Non- } \\
\text { randomized } \\
\text { controlled trial }\end{array}$ & $\begin{array}{l}\text { Saneum Natural } \\
\text { Recreation } \\
\text { Forest }\end{array}$ & $\begin{array}{l}\text { T1: Just before } \\
\text { treatment; T2: just } \\
\text { after treatment }\end{array}$ \\
\hline Lim 2014 & $\begin{array}{l}\text { Elderly people } \\
\text { from a nursing } \\
\text { facility }\end{array}$ & $\geq 50$ & 29.7 & $\begin{array}{l}\text { Activities included strolling in the } \\
\text { forest, experiencing five senses, } \\
\text { games, and meditation. }\end{array}$ & Eleven weeks & $\begin{array}{l}\text { Once a week } \\
\text { for } 90 \text { min. }\end{array}$ & 22 & $\begin{array}{l}\text { 1: }(N=21) \text { Similar } \\
\text { activities in a hospital; } \\
2:(N=21) \text { Normal } \\
\text { daily routines }\end{array}$ & $\begin{array}{l}\text { Geriatric depression } \\
\text { scale short form- } \\
\text { Korea version }\end{array}$ & $\begin{array}{l}\text { Non- } \\
\text { randomized } \\
\text { controlled trial }\end{array}$ & Forest & $\begin{array}{l}\text { T1: Just before } \\
\text { treatment; T2: just } \\
\text { after treatment }\end{array}$ \\
\hline You 2014 & $\begin{array}{l}\text { Middle-aged } \\
\text { women }\end{array}$ & $\sim 50$ & 100 & $\begin{array}{l}\text { Sallimyok (Forest Therapy); } \\
\text { meditation; walking; Qi-Qong. }\end{array}$ & Two days & All days & 10 & $\begin{array}{l}(N=10) \text { Normal daily } \\
\text { routines }\end{array}$ & $\begin{array}{l}\text { Zung Self-Rating } \\
\text { Depression Scale }\end{array}$ & $\begin{array}{l}\text { Non- } \\
\text { randomized } \\
\text { controlled trial }\end{array}$ & Forest & $\begin{array}{l}\text { T1: Just before } \\
\text { treatment; T2: just } \\
\text { after treatment }\end{array}$ \\
\hline Choi 2014 & Cancer patients & $\geq 50$ & 75.47 & $\begin{array}{l}\text { Activities included meditation, } \\
\text { touching and lying on the wood, } \\
\text { and treasure hunt. }\end{array}$ & Eight weeks & $\begin{array}{l}\text { Once a week } \\
\text { for } 120 \mathrm{~min} .\end{array}$ & 26 & $\begin{array}{l}(N=27) \text { Normal daily } \\
\text { routines }\end{array}$ & $\begin{array}{l}\text { Zung Self-Rating } \\
\text { Depression Scale }\end{array}$ & $\begin{array}{l}\text { Non- } \\
\text { randomized } \\
\text { controlled trial }\end{array}$ & Urban forest & $\begin{array}{l}\text { T1: Just before } \\
\text { treatment; T2: just } \\
\text { after treatment }\end{array}$ \\
\hline Shin 2012 & $\begin{array}{l}\text { Detoxified } \\
\text { chronic } \\
\text { alcoholics }\end{array}$ & 45.26 & 8.7 & $\begin{array}{l}\text { Three days actively interacting } \\
\text { with nature, three days challenging } \\
\text { activities in nature, three days } \\
\text { activities for introspection (e.g. } \\
\text { nature meditation, counseling in } \\
\text { nature). }\end{array}$ & Nine days & All days & 47 & $\begin{array}{l}(N=45) \text { Normal daily } \\
\text { routines }\end{array}$ & BDI & $\begin{array}{l}\text { Randomized } \\
\text { controlled trial }\end{array}$ & $\begin{array}{l}\text { Saneum } \\
\text { Recreational } \\
\text { Forest }\end{array}$ & $\begin{array}{l}\text { T1: Just before } \\
\text { treatment; T2: just } \\
\text { after treatment }\end{array}$ \\
\hline Chun 2017 & $\begin{array}{l}\text { Chronic stroke } \\
\text { patients }\end{array}$ & 60.8 & 32.2 & $\begin{array}{l}\text { Activities included meditation, } \\
\text { experiencing the forest through all } \\
\text { five senses, and walking. }\end{array}$ & Four days & All days & 30 & $\begin{array}{l}(N=29) \text { Similar } \\
\text { activities in an urban } \\
\text { area }\end{array}$ & BDI and HDRS-17 & $\begin{array}{l}\text { Randomized } \\
\text { controlled trial }\end{array}$ & $\begin{array}{l}\text { Recreational } \\
\text { forest }\end{array}$ & $\begin{array}{l}\text { T1: Just before } \\
\text { treatment; T2: just } \\
\text { after treatment }\end{array}$ \\
\hline$\frac{\text { M.-H. Kim }}{\underline{2015}}$ & $\begin{array}{l}\text { Psychiatric } \\
\text { Inpatients }\end{array}$ & 46.91 & 50 & $\begin{array}{l}\text { Forest activities included } \\
\text { handkerchief dyeing, decorating a } \\
\text { frame using natural items, and } \\
\text { group work. }\end{array}$ & Two weeks & $\begin{array}{l}\text { Five times (60 } \\
\text { min each time) }\end{array}$ & 10 & $\begin{array}{l}(N=10) \text { Treatment as } \\
\text { usual }\end{array}$ & BDI & $\begin{array}{l}\text { Non- } \\
\text { randomized } \\
\text { controlled trial }\end{array}$ & $\begin{array}{l}\text { Jeonnam Forest } \\
\text { Resources } \\
\text { Research } \\
\text { Center } \\
\end{array}$ & $\begin{array}{l}\text { T1: } 5 \text { to } 10 \text { minutes } \\
\text { before treatment; } \\
\text { T2: } 5 \text { to } 10 \text { minutes } \\
\text { after treatment; }\end{array}$ \\
\hline $\begin{array}{l}\frac{\text { Y. G. Kim }}{2015} \\
\underline{2}\end{array}$ & Cancer patients & $-\ldots--$ & 84.90 & $\begin{array}{l}\text { Experiencing feeling (1st day), } \\
\text { meditation ( } 2 \text { nd day), mindfulness } \\
\text { (3rd day), and feedback. }\end{array}$ & Three days & $\begin{array}{l}\text { All days for } \\
\text { four hours a day }\end{array}$ & 27 & $\begin{array}{l}(N=26) \text { Normal daily } \\
\text { routines }\end{array}$ & $\begin{array}{l}\text { Hospital Anxiety and } \\
\text { Depression Scale }\end{array}$ & $\begin{array}{l}\text { Non- } \\
\text { randomized } \\
\text { controlled trial }\end{array}$ & Forest & $\begin{array}{l}\text { T1: Just before } \\
\text { treatment; T2: just } \\
\text { after treatment }\end{array}$ \\
\hline$\underline{\text { Hong } 2013}$ & $\begin{array}{l}\text { Psychiatric } \\
\text { outpatients with } \\
\text { mild cognitive } \\
\text { impairment }\end{array}$ & 57.46 & 83.33 & $\begin{array}{l}\text { Activities in forests included taking } \\
\text { herbal medicine, music therapy, } \\
\text { and Qigong. }\end{array}$ & Three days & $\begin{array}{l}\text { All days, } \\
\text { several hours } \\
\text { per day }\end{array}$ & 15 & $\begin{array}{l}(N=15) \text { Conducted } \\
\text { regular diet and } \\
\text { exercise program ( } 3 \\
\text { times a day) in the } \\
\text { forest }\end{array}$ & BDI & Crossover trial & $\begin{array}{l}\text { Saneum Natural } \\
\text { Recreation } \\
\text { Forest }\end{array}$ & $\begin{array}{l}\text { T1: Just before } \\
\text { treatment; T2: just } \\
\text { after treatment }\end{array}$ \\
\hline Hong 2012 & $\begin{array}{l}\text { Hwa-Byung } \\
\text { patients }\end{array}$ & 51.6 & 90 & $\begin{array}{l}\text { Activities in forests included taking } \\
\text { herbal medicine, music therapy, } \\
\text { and Qigong. }\end{array}$ & Three days & $\begin{array}{l}\text { All days, } \\
\text { several hours } \\
\text { per day }\end{array}$ & 16 & $\begin{array}{l}(N=16) \text { Conducted } \\
\text { regular diet and } \\
\text { exercise program ( } 3 \\
\text { times a day) in the } \\
\text { forest }\end{array}$ & BDI & Crossover trial & $\begin{array}{l}\text { Saneum Natural } \\
\text { Recreation } \\
\text { Forest }\end{array}$ & $\begin{array}{l}\text { T1: Just before } \\
\text { treatment; T2: just } \\
\text { after treatment }\end{array}$ \\
\hline
\end{tabular}




\begin{tabular}{|c|c|c|c|c|c|c|c|c|c|c|c|c|}
\hline Woo 2012 & $\begin{array}{l}\text { Patients with } \\
\text { major } \\
\text { depression } \\
\text { taking } \\
\text { antidepressants }\end{array}$ & 45.68 & --- & $\begin{array}{l}\text { Forest activities included } \\
\text { cognitive-behavioral therapy, } \\
\text { meditation, and relaxation training. }\end{array}$ & Four weeks & $\begin{array}{l}\text { Once a week } \\
\text { (for } 3 \text { hours) }\end{array}$ & 28 & $\begin{array}{l}\text { 1: }(N=21) \text { Similar } \\
\text { activities in a hospital; } \\
\text { 2: }(N=15) \text { Treatment } \\
\text { as usual; } \\
\text { 3: }(N=17) \text { Walking in } \\
\text { a forest. }\end{array}$ & $\begin{array}{l}\text { HDRS-17, MADRS, } \\
\text { and BDI }\end{array}$ & $\begin{array}{l}\text { Randomized } \\
\text { controlled trial }\end{array}$ & $\begin{array}{l}\text { Seoul } \\
\text { Arboretum }\end{array}$ & $\begin{array}{l}\text { T1: Just before } \\
\text { treatment; T2: just } \\
\text { after treatment }\end{array}$ \\
\hline Bang 2018 & $\begin{array}{l}\text { Elementary- } \\
\text { school students } \\
\text { in grades } 4 \text { to } 6 \\
\text { at five } \\
\text { community } \\
\text { centers }\end{array}$ & 11.79 & 55.56 & $\begin{array}{l}\text { Forest activities included five } \\
\text { senses experience, walking, and } \\
\text { games. }\end{array}$ & Ten weeks & $\begin{array}{l}\text { Once a week } \\
\text { (for } 60 \mathrm{~min} \text { ) }\end{array}$ & 24 & $\begin{array}{l}(N=28) \text { Normal daily } \\
\text { routines }\end{array}$ & $\begin{array}{l}\text { Children's } \\
\text { Depression } \\
\text { Inventory }\end{array}$ & $\begin{array}{l}\text { Non- } \\
\text { randomized } \\
\text { controlled trial }\end{array}$ & Urban forest & $\begin{array}{l}\text { T1: Just before } \\
\text { treatment; T2: just } \\
\text { after treatment }\end{array}$ \\
\hline Kim 2009 & $\begin{array}{l}\text { Patients with } \\
\text { major } \\
\text { depression } \\
\text { taking } \\
\text { antidepressants }\end{array}$ & 46.2 & 85.7 & $\begin{array}{l}\text { Forest activities included } \\
\text { cognitive-behavioral therapy, } \\
\text { positive psychology tools, and } \\
\text { mindfulness meditation on breath, } \\
\text { wind, forest, and sounds. }\end{array}$ & Four weeks & $\begin{array}{l}\text { Once a week } \\
\text { (three } \\
\text { hours/session) }\end{array}$ & 23 & $\begin{array}{l}\text { 1: }(N=19) \text { Similar } \\
\text { activities in a hospital; } \\
\text { 2: }(N=21) \text { Treatment } \\
\text { as usual. }\end{array}$ & $\begin{array}{l}\text { BDI, HDRS, } \\
\text { MADRS }\end{array}$ & $\begin{array}{l}\text { Randomized } \\
\text { controlled trial }\end{array}$ & $\begin{array}{l}\text { Hong-Reung; } \\
\text { 44-ha } \\
\text { arboretum }\end{array}$ & $\begin{array}{l}\text { T1: Just before } \\
\text { treatment; T2: } \mathrm{T} 1+ \\
\text { 1 week; } \\
\text { T3: T1 + } 2 \text { weeks; } \\
\text { T4: T1 + } 3 \text { weeks }\end{array}$ \\
\hline
\end{tabular}

Note: *When results for more than one outcome measure were available, we gave preference to results from one outcome measure based on specific criteria (see Supplementary File p. 2 for more information). The chosen measures are in bold. Underlined studies were written in Korean. BDI = Beck Depression Inventory; HDRS = Hamilton Depression Rating Scale; MADRS = Montgomery-Asberg Depression Rating Scale. 
Table 4. Percentage of reduction in depressive symptoms from baseline for forest therapy and other interventions, listed by primary study

\begin{tabular}{|c|c|c|c|c|c|c|}
\hline \multirow{2}{*}{$\begin{array}{c}\text { First author and } \\
\text { year }\end{array}$} & \multicolumn{6}{|c|}{ Groups } \\
\hline & Forest therapy & $\begin{array}{c}\text { Similar activities in a } \\
\text { hospital }\end{array}$ & $\begin{array}{c}\text { Similar activities in an } \\
\text { urban area }\end{array}$ & $\begin{array}{c}\text { No intervention/usual } \\
\text { care }\end{array}$ & $\begin{array}{l}\text { Diet plus exercise in the } \\
\text { forest }\end{array}$ & $\begin{array}{c}\text { Walking in a } \\
\text { forest }\end{array}$ \\
\hline \multicolumn{7}{|c|}{ Randomized controlled trials } \\
\hline Chun 2017 & -77.46 & NA & -1.39 & NA & NA & NA \\
\hline Kim 2009 & -50.08 & -19.91 & NA & -7.57 & NA & NA \\
\hline Shin 2012 & -64.04 & NA & NA & 0.20 & NA & NA \\
\hline Woo 2012 & -50.27 & -34.81 & NA & -10.10 & NA & -32.49 \\
\hline Mean $(S D)$ & $-60.46(13.08)$ & $-27.36(10.54)$ & -1.39 & $-5.82(5.37)$ & NA & -32.49 \\
\hline Median & -57.16 & -27.36 & -1.39 & -7.57 & NA & -32.49 \\
\hline \multicolumn{7}{|c|}{ Cross-over trials } \\
\hline Hong 2013 & -46.43 & NA & NA & NA & -5.10 & NA \\
\hline Hong 2012 & -56.04 & NA & NA & NA & -9.91 & NA \\
\hline Mean $(S D)$ & $-51.24(6.80)$ & NA & NA & NA & $-7.51(3.40)$ & NA \\
\hline Median & -51.24 & NA & NA & NA & -7.51 & NA \\
\hline \multicolumn{7}{|c|}{ Non-randomized controlled trials } \\
\hline Han 2016 & -46.08 & NA & NA & -15.85 & NA & NA \\
\hline $\operatorname{Lim} 2014$ & -27.71 & -16.76 & NA & 2.18 & NA & NA \\
\hline You 2014 & -27.62 & NA & NA & -0.58 & NA & NA \\
\hline Choi 2014 & -9.61 & NA & NA & 3.43 & NA & NA \\
\hline M.-H. Kim 2015 & -13.03 & NA & NA & 6.99 & NA & NA \\
\hline Y. G. Kim 2015 & -9.79 & NA & NA & 3.93 & NA & NA \\
\hline $\operatorname{Mean}(S D)$ & $-22.31(14.33)$ & -16.76 & NA & $0.02(8.15)$ & NA & NA \\
\hline Median & -20.33 & -16.76 & NA & 2.81 & NA & NA \\
\hline \multicolumn{7}{|c|}{ Non-randomized controlled trial with children } \\
\hline Bang 2018 & -21.13 & NA & NA & -8.73 & NA & NA \\
\hline
\end{tabular}


Table 5. Aggregated sample size $(N)$ and studies providing data for each comparison

\begin{tabular}{|l|c|l|}
\hline \multicolumn{1}{|c|}{ Comparison } & N & \multicolumn{1}{|c|}{ Primary studies' first author and year } \\
\hline $\begin{array}{l}\text { Forest therapy versus no } \\
\text { intervention/usual care }\end{array}$ & 525 & $\begin{array}{l}\text { Kim 2009; Woo 2012; Shin 2012; You } \\
\text { 2014; Lim 2014; Choi 2014; M-H. Kim } \\
\text { 2015; Y-G. Kim 2015; Bang 2018 }\end{array}$ \\
\hline $\begin{array}{l}\text { Forest therapy versus similar } \\
\text { activities in a hospital }\end{array}$ & 134 & Kim 2009; Woo 2012; Lim 2014 \\
\hline $\begin{array}{l}\text { Forest therapy versus similar } \\
\text { activities in an urban area }\end{array}$ & 59 & Chun 2017 \\
\hline $\begin{array}{l}\text { Forest therapy versus diet plus } \\
\text { forest-based exercise }\end{array}$ & 31 & $\underline{\text { Hong 2013; Hong 2012 }}$ \\
\hline $\begin{array}{l}\text { Forest therapy versus walking in } \\
\text { a forest }\end{array}$ & 43 & Woo 2012 \\
\hline
\end{tabular}

Note: Some forest therapy groups were counted in more than one comparison. Randomized controlled trials are in bold and cross-over trials are underlined. The other studies are nonrandomized controlled trials. 


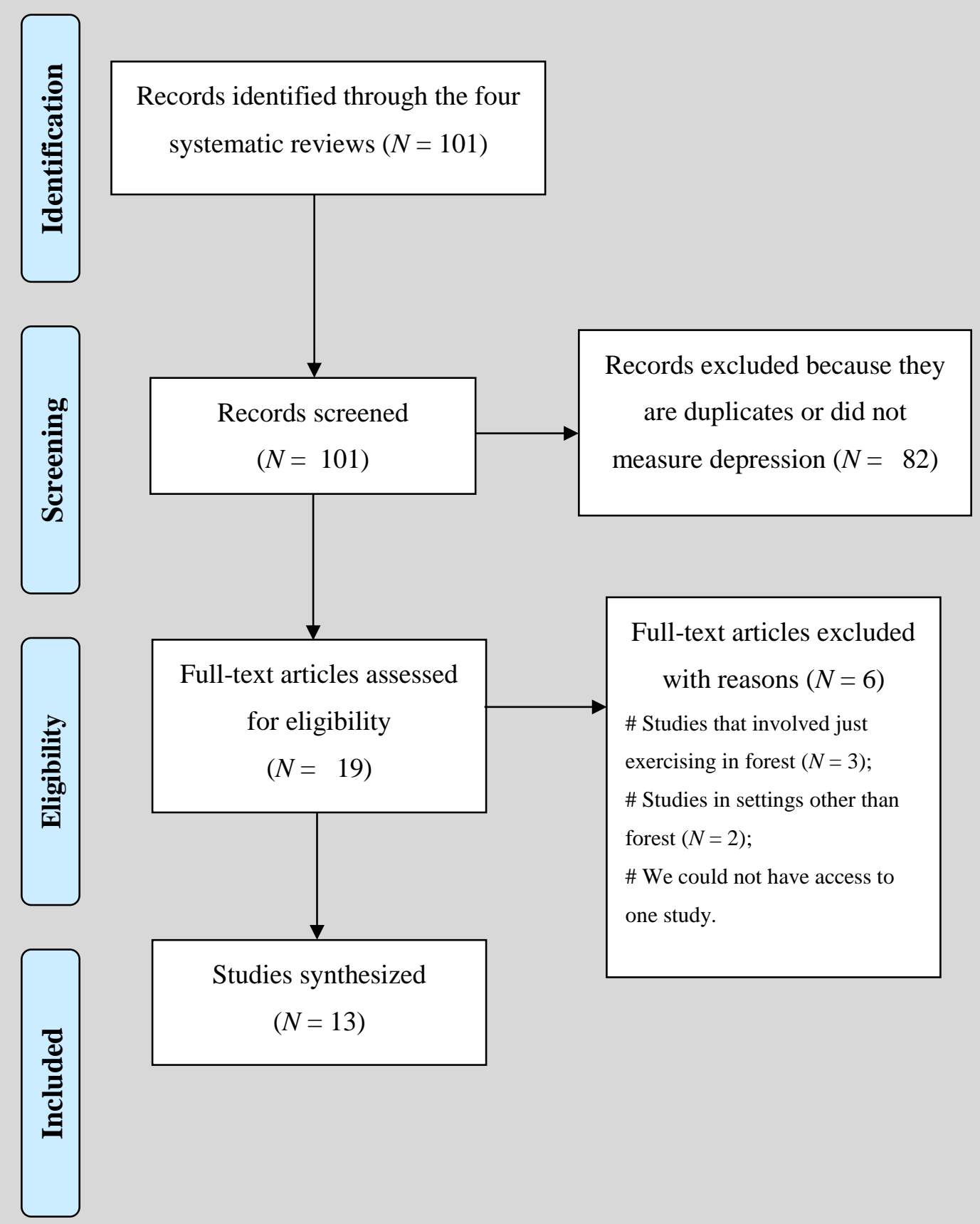

Fig. 1. Flow diagram illustrating the selection process of primary studies. 


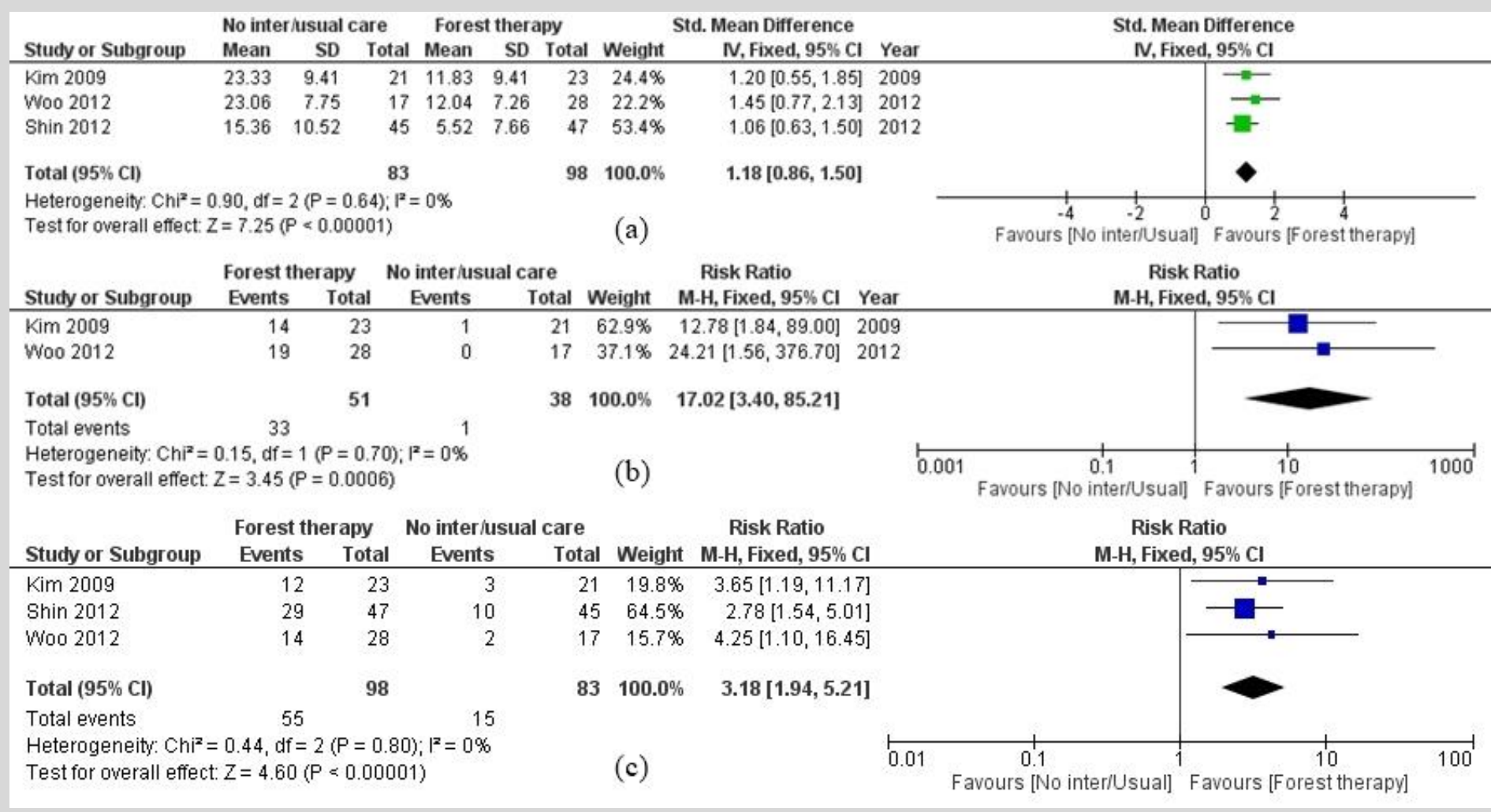

Fig. 2. Results of randomized controlled trials: (a) Comparison of the post-intervention mean score of forest therapy groups versus no intervention/usual care using the inverse variance fixed-effect meta-analysis. (b) Comparison of the risk of temporary recovery from depression (i.e. remission) between forest therapy groups and usual care for depression groups, using the Mantel-Haenszel fixed-effect meta-analysis. (c) Comparison of the risk of response to treatment (i.e. $\geq 50 \%$ reduction on depressive symptoms) between forest therapy groups and no intervention/usual care groups, using the Mantel-Haenszel fixed-effect meta-analysis. Events refer to cases of remission (b) or response (c). Green squares refer to standardized mean differences and blues squares to risk ratios. Bigger squares indicated more participants in a study or more events and a bigger diamond indicates greater uncertainty in the estimate. Crossovers and non-randomized controlled trials were analyzed separately. 


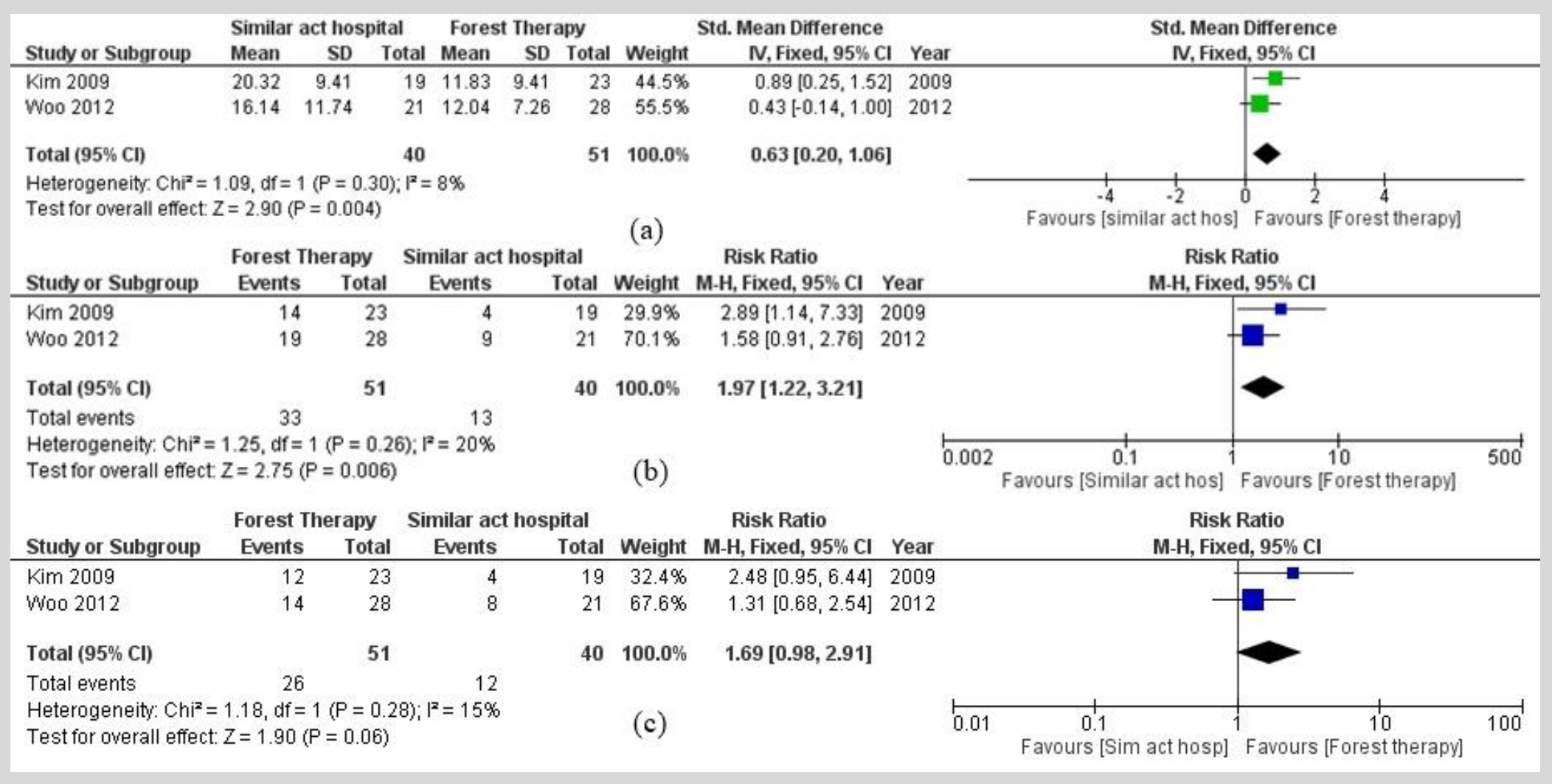

Fig. 3. Results of randomized controlled trials: (a) Comparison of the post-intervention mean score of forest therapy groups versus similar activities in hospital groups using the inverse variance fixed-effect meta-analysis. (b) Comparison of the risk of temporary recovery from depression (i.e. remission) between forest therapy groups and similar activities in hospital groups, using the Mantel-Haenszel fixed-effect meta-analysis. (c) Comparison of the risk of response to treatment (i.e. $\geq 50 \%$ reduction on depressive symptoms) between forest therapy groups and similar activities in hospital groups, using the Mantel-Haenszel fixed-effect meta-analysis. Events refer to cases of remission (b) or response (c). Green squares refer to standardized mean differences and blues squares to risk ratios. Bigger squares indicated more participants in a study or more events and a bigger diamond indicates greater uncertainty in the estimate. Cross-over and non-randomized controlled trials were analyzed separately. 